\title{
A Survey of Bedbug (Cimex lectularius) Infestation in Some Homes and Hostels in Gboko, Benue State, Nigeria
}

\author{
Onah Isegbe Emmanuel, Alu Cyprian, and Omudu Edward Agbo \\ Department of Biological Sciences, Benue State University, AGC, P.O. Box 5, Wadata Makurdi, Nigeria \\ Correspondence should be addressed to Onah Isegbe Emmanuel; isegbeonah@gmail.com
}

Received 15 February 2014; Revised 11 April 2014; Accepted 14 April 2014

Academic Editor: Cleber Galvão

Copyright (C) 2014 Onah Isegbe Emmanuel et al. This is an open access article distributed under the Creative Commons Attribution License, which permits unrestricted use, distribution, and reproduction in any medium, provided the original work is properly cited.

\begin{abstract}
A Survey of bed bug infestation in some homes and hostels, in Gboko, Benue State, Nigeria, was conducted from January to April, 2011. Bed frames, bunks, mattresses, pillows, chairs, and clothes were inspected. A total of 2,642 bed bugs were collected. $73.3 \%$ were from hostels while $26.7 \%$ were from homes. There was a significant difference between in the number of homes infested and those not infested $\left(\chi^{2}=61.44, \mathrm{df}=4, P<0.05\right)$. Nymphs were the most populated, with $292(41.4 \%)$, followed by males $223(31.6 \%)$, and females $190(27.0 \%)$. There was no significant difference in the number of infested hostels and those not infested $\left(\chi^{2}=0.8\right.$, $\mathrm{df}=4, P<0.05)$. The nymphs being the most populated with $901(64.1 \%)$, followed by males $538(36.1 \%)$, and then females 496 (35.3\%). The greater number of infestation recorded in the hostels was as a result of poor hygiene, lack of adequate knowledge of the best control practices and the high population density. In homes, lack of the awareness of the resurgence of the emerging pest and lack of proper health education is responsible for the high infestation. Proactive approach should be taken towards public health education against bed bug infestation. Government and NGOs should take critical steps in preventing spread and stigma.
\end{abstract}

\section{Introduction}

Bedbugs are small parasitic insects of the family Cimicidae (most commonly Cimex lectularius). Two species are associated with humans, Cimex lectularius and Cimex hemipterus, which are cosmopolitan or found in tropical and subtropical regions, respectively [1]. Bedbugs are blood sucking ectoparasites that infest human habitations and usually feed during the night when the host is sleeping [2]. Under optimal conditions, the adult bedbug feeds once a week. The major attractants appear to be human body temperature and carbon dioxide production and also by certain chemicals [2].

Bedbug infestation associated problems include lack of sleep and psychological and social distress from society's stigma concerning pests [2]. Although bedbugs have not been linked to disease transmission, they have been shown to harbor the causative organisms of plague, relapsing fever tularemia, Q fever, and Wolbachia. Symptoms from their bites include severe irritation, itching, inflammation, and swelling of the skin [3].
Special nocturnal search is often required as the definitive diagnosis depends upon collection and identification of bedbugs [1].

In the 1980's bedbugs were considered relatively uncommon in many developed countries, such as the UK probably due to better building practices, better education, and emphasis on wide use of insecticides [4]. In developing countries, bedbug infestation is at a high level [5]. Recent observations suggest that urban settings have experienced increased infestation over the past 10 years [6-8]. There is also recent evidence for insecticide resistance in bed bugs in addition to effective application techniques [9-13]. An increasing poor attitude towards housekeeping and poor hygiene is responsible for a high infestation in Makurdi and Otukpo [14].

This survey was carried out to determine the status of bed bug infestation in Gboko, with a view to investigate control measures adopted by residents against the pest; as well as their knowledge on the hazards associated with harboring bedbugs. 
TABLE 1: Sex and growth stage of bedbugs (Cimex lectularius) collected from homes in Gboko.

\begin{tabular}{|c|c|c|c|c|c|c|c|}
\hline $\begin{array}{l}\text { Location } \\
\text { Gboko }\end{array}$ & $\begin{array}{l}\text { Number of } \\
\text { homes } \\
\text { inspected }\end{array}$ & $\begin{array}{l}\text { Number of } \\
\text { homes } \\
\text { infested (\%) }\end{array}$ & Males (\%) & Females (\%) & Nymphs (\%) & $\begin{array}{c}\text { Total number } \\
\text { of bedbugs } \\
(\%)\end{array}$ & Eggs (\%) \\
\hline Central & 107 & $12(11.2)$ & $42(31.8)$ & $30(22.7)$ & $60(45.5)$ & $132(18.7)$ & $313(16.6)$ \\
\hline East & 101 & $7(6.9)$ & $2(24.2)$ & $18(19.8)$ & $51(56.0)$ & $91(12.9)$ & $273(14.5)$ \\
\hline West & 118 & $20(16.9)$ & $50(27.5)$ & $60(33.0)$ & $72(40.0)$ & $182(25.8)$ & $401(21.3)$ \\
\hline North & 132 & $38(28.8)$ & $73(33.0)$ & $67(30.3)$ & $81(36.7)$ & $221(31.3)$ & $701(37.2)$ \\
\hline South & 142 & $9(6.3)$ & $36(45.6)$ & $15(19.0)$ & $28(35.4)$ & 79 (11.2) & $196(10.4)$ \\
\hline Total & 600 & 86 & 223 & 190 & 292 & 705 & $1884(100)$ \\
\hline
\end{tabular}

TABLE 2: Sex and growth stage of bedbugs (Cimex lectularius) collected from Hostels in Gboko.

\begin{tabular}{|c|c|c|c|c|c|c|c|}
\hline $\begin{array}{l}\text { Location } \\
\text { Gboko }\end{array}$ & $\begin{array}{l}\text { Number of } \\
\text { Hostels } \\
\text { Inspected }\end{array}$ & $\begin{array}{c}\text { Number of } \\
\text { homes } \\
\text { Infested (\%) }\end{array}$ & Males (\%) & Females (\%) & Nymphs (\%) & $\begin{array}{c}\text { Total number of } \\
\text { bedbugs }(\%)\end{array}$ & Eggs (\%) \\
\hline Central & 2 & $1(50.0)$ & $59(19.0)$ & $48(15.5)$ & $203(65.5)$ & $310(16.0)$ & 307 (21.8) \\
\hline East & 2 & $1(50.0)$ & $78(25.0)$ & $81(26.0)$ & $153(49.0)$ & $312(16.1)$ & $178(12.7)$ \\
\hline West & 1 & $1(100.0)$ & $111(27.8)$ & $107(26.8)$ & $182(25.5)$ & $400(20.7)$ & $341(24.3)$ \\
\hline North & 2 & $2(100.0)$ & 198 (32.9) & $201(33.4)$ & $201(33.4)$ & $602(31.1)$ & $301(21.4)$ \\
\hline South & 2 & $1(50.0)$ & $92(29.4)$ & $59(18.4)$ & $162(51.8)$ & $313(16.2)$ & $279(19.8)$ \\
\hline Total & 9 & 6 & 538 & 496 & 901 & 1937 & $1406(100)$ \\
\hline
\end{tabular}

\section{Materials and Method}

The survey was conducted in Gboko, Local Government area of Benue state, Nigeria, from January to April, 2011. Gboko is located on $7^{\circ} 19^{\prime} 30^{\prime \prime} \mathrm{N} 9^{\circ} 0^{\prime} 18^{\prime \prime} \mathrm{E}$ and lies in the Savanna region of North-Central Nigeria, with a temperature range from $29^{\circ} \mathrm{C}$ to $33^{\circ} \mathrm{C}$. It has a population of over 500,000 people who are predominantly farmers and civil servants. They speak Tiv and English language. Benue State covers an area of about $34,059 \mathrm{~km}^{2}$ with a population of over 4.2 million people.

Written informed consent was obtained from the Gboko Local Government Health Authority and verbal consent from heads of household heads and owners of hostels. Randomly selected homes and hostels were visited and bed frames, mattresses, bamboo beds, carpets, mosquito nets, benches, walls, cushioned chairs, pillows, and bed sheets were thoroughly inspected for bedbugs infestation. Collecting bottles, paint-like brushes, and 70\% alcohol were the materials used. Where bedbugs were seen, they were brushed into the collecting bottles. The material from which the bedbug was collected was noted and the number of bedbugs collected per material was noted. Residents were interviewed on the control measures adopted against bedbugs. The specimens transferred to the General Zoology Laboratory of the Benue State University for identification according to published keys by Pratt and Smith [15].

\section{Result}

Out of the 600 homes and 9 hostels surveyed, 86 (14.3\%) homes and $6(66.7 \%)$ hostels were infested with bedbugs. A total of 705 bedbugs were collected from homes, comprising 223 (31.6\%) males, 190 (27.0\%) females, and 292 (41.4\%) nymphs. 1884 eggs were also collected. A total of 1937 beg bugs were collected from hostels. This comprises $538(27.8 \%)$ males, 496 (25.6\%) females, and 901 (46.5\%) nymphs.

A total of 2,642 bedbugs were collected from all the hostels and homes, comprising 761 (28.8\%) males and 686 (26.0\%) females and 1,193 (45.2\%) nymphs alongside 3290 eggs. $73.3 \%$ of the total collected bedbugs were from hostels while $26.7 \%$ of the total bedbugs were from residential homes. Gboko North had the highest number of infestation rate of $221(31.3 \%)$ in residential homes and $602(31.1 \%)$ in hostels, while Gboko South had the least infestation rate of 79 (11.2\%) in residential homes and $313(16.2 \%)$ in hostel (Tables 1 and 2). There was a significant difference between the number of infested and uninfested homes. In the residential homes $\left(\chi_{\text {calculated }}^{2}=61.44, \mathrm{df}=4, \chi_{\text {Tabulated }}^{2}=4.278\right.$ at $95 \%$ level of significance). In the hostels there was no significant difference between the number of infested and uninfested hostels $\left(\chi_{\text {calculated }}^{2}=0.8, \mathrm{df}=4, \chi_{\text {Tabulated }}^{2}=4.278\right.$ at $95 \%$ level of significance). 
A total of 3,602 items were inspected, out of which $760(21.1 \%)$ items were infested. Bed frames had highest infestation; out of 700 inspected bed frames, 314 (44.9\%) were infested with a total number of 1,356 bedbugs. 11 bamboo beds were inspected and only $9(81.8 \%)$ were infested with a total number 28 bedbugs (Table 3 ).

The survey of different control measures used at different sites revealed a total of 8 different control measures. A total of 600 homes use one or more of the measures. Those who use Nuvan, dichlorvos (2,2-dichlorovinyl dimethyl phosphate) had the highest frequency of $196(164.0 \%)$ while those who use Omo (detergent) and soap had the least frequency of 27 (22.2\%) (Table 4). Insect powder is mostly used outdoors, and furniture assumed to be infested is taken away from the main building and the powder is applied to harborages. Snipper and Nuvan are applied inside houses mostly at night. Similarly, syringes are used to spray the insecticide in corners of the house where the pest is likely to be hiding. The same insecticide is also used with the aim at controlling other insects in the houses visited.

\section{Discussion}

This survey recorded a high rate of infestation of bedbug. This agrees with the other findings in Australia $[7,8]$, in Canada [16], and in Benue State, Nigeria [14].

This is as a result of the increase in the movement of people (including students from holidays and prisoners) from where infestation is very common via infested luggage, clothing, and other personal belongings and the increasing movement of bedding, furniture, and other materials by foot, car, and train. Recent increase in incidence of bedbug infestations in Canada, Italy, UK, USA and many other developed western countries has been linked to increase in international travel and the reduction in the use of insecticides to control cockroaches and ants (TerPoorten and Prose, 2005). 85.8\% of the very recent cases of bedbug infestations recorded in Central Italy were recorded in apartment that housed immigrants and tourists from Mediterranean countries [17].

The data collected indicated high percentage of males than females and yielded greater percentage of nymphs. This agrees with a finding in Gbajimba, a settlement in Benue, where records show a greater percentage of males than females [14]. The greater percentage of nymphs recorded is an indication of the possibility of an increase in infestation where the right control measures are not employed. The greatest percentage of eggs points to a possible persistence of infestation by adult females. This percentage may be due to treatments applied which might have killed some adults without affecting the eggs.

The infestations were highest in bed frames; these include single or double bunk (iron beds) frames and wooden bed frames. This is as a result of conducive hiding places the harborage provide and their close proximity to their feeding or host location. This however disagrees with Doggett's findings, who indicated that iron bed harbor less bedbugs in his survey [7].
TABLE 3: Distribution of bedbugs in different harborages in homes and hostels in Gboko.

\begin{tabular}{lccc}
\hline Harborages & $\begin{array}{c}\text { Total number } \\
\text { of harborages }\end{array}$ & $\begin{array}{c}\text { Number of } \\
\text { harborages with } \\
\text { bedbugs }(\%)\end{array}$ & $\begin{array}{c}\text { Total } \\
\text { Number } \\
\text { of bedbug }\end{array}$ \\
\hline Bed frames & 700 & $314(44.9)$ & 1,356 \\
Mattresses & 905 & $192(21.2)$ & 603 \\
Pillows & 800 & $93(11.6)$ & 262 \\
Carpets & 26 & $13(50.0)$ & 62 \\
Walls & 600 & $86(14.3)$ & 157 \\
Wooden chairs & 107 & $14(13.1)$ & 53 \\
Wooden benches & 36 & $9(25.0)$ & 24 \\
Bamboo beds & 11 & $9(81.8)$ & 28 \\
Executive chairs & 217 & $13(6.0)$ & 36 \\
Other Furniture & 200 & $17(8.5)$ & 61 \\
\hline Total & 3,602 & 760 & 2,642 \\
\hline
\end{tabular}

The percentage recorded in hostels is probably due to poor or bad housekeeping and poor hygiene which is very common in Gboko. The World Health Organization suggests that poor housekeeping encourages bedbug breeding [18].

A review of the control measures (treatment) used at different sites indicated a high percentage on the use of Nuvan (2,2-dichloroethenyl phosphate) as it was the chemical method that was easily and readily available and affordable by most residents. Lack of technical knowledge of the control measures, knowledge of their hiding places, knowledge of resistance of eggs to spraying insecticides, and wrong use of the insecticides may have contributed to the high rate of infestation $[4,9-11,13]$.

Infestation of bedbugs in homes and students hostels is epidemiologically significant. The nuisance they cause may result into sleeplessness, anxiety, and insomnia which could affect concentration in school and work.

The high infestation is likely to arise from greater dispersal of bed bugs, control strategies that are not fully effective, partial treatments that disrupt but do not eradicate infestation are used which fragment and spread bed bug colonies rather than disintegrating them. The research indicates that most people have little knowledge about bed bug control measures.

Conclusively high rate of bedbug infestation recorded in some homes and hostels is no doubt a reflection of poor hygiene, sanitation, and lack of adequate knowledge concerning the pest.

It is important that proactive approach should be taken on public education and awareness against bedbug. Critical steps in preventing bedbug spread and stigma should be taken up by the government and nongovernmental organizations. Training is an important component that should be offered and tailored to stakeholders, like property owners, pest management professionals, and staff working in the residential setting. 


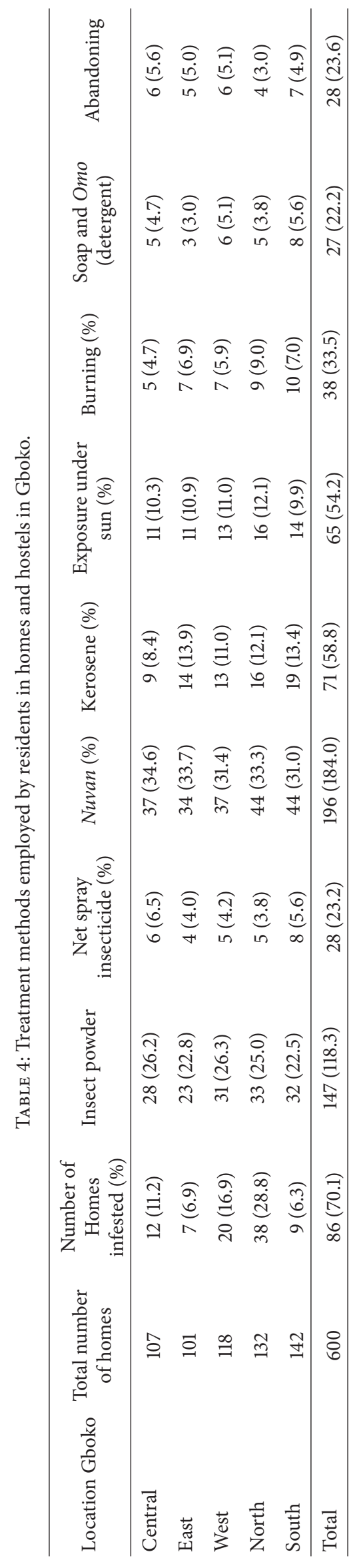




\section{Conflict of Interests}

The authors declare that there is no conflict of interests regarding the publication of this paper.

\section{References}

[1] K. Reinhardt and M. T. Siva-Jothy, "Biology of the bed bugs (Cimicidae)," Annual Review of Entomology, vol. 52, pp. 351-374, 2007.

[2] I. Thomas, G. C. Kihiczak, and R. A. Schwartz, "Bedbug bites: a review," International Journal of Dermatology, vol. 43, no. 6, pp. 430-433, 2004.

[3] S. Tharakaram, "Bullous eruption due to Cimex lecticularis," Clinical and Experimental Dermatology, vol. 24, no. 3, pp. 241242, 1999.

[4] M. F. Potter, "The business of bedbug," Pest Management Professional, vol. 76, no. 1, pp. 28-44, 2008.

[5] E. Panagiotakopulu and P. C. Buckland, "Cimex lectularius L., the common bed bug from Pharaonic Egypt," Antiquity, vol. 73, no. 282, pp. 908-911, 1999.

[6] C. Boase, J. Small, and R. Naylor, Interim Report on Insecticide Susceptibility Status of UK Bedbugs. Professional Pest Controller, 2004.

[7] S. L. Doggett, A Code of Practice for the Control of Bed Bug Infestations in Australia, vol. 5, Bed Bug Code of Practice Working Group, Australian Environmental Pest Managers Association, New South Wales, Australia, 2004.

[8] N. Ryan, B. Peters, and P. Miller, "A survey of bedbugs in short stay lodges," New South Wales Public Health Bulletin, vol. 15, no. 11-12, pp. 215-217, 2004.

[9] H. Harlan, M. Faulde, and G. Gaumann, Bed Bugs, Health Significance of Urban Pets, 2008.

[10] E. A. Temu, J. N. Minjas, C. J. Shiff, and A. Majala, "Bedbug control by permethrin-impregnated bednets in Tanzania," Medical and Veterinary Entomology, vol. 13, no. 4, pp. 457-459, 1999.

[11] J. Myamba, C. A. Maxwell, A. Asidi, and C. F. Curtis, "Pyrethroid resistance in tropical bedbugs, Cimex hemipterus, associated with use of treated bednets," Medical and Veterinary Entomology, vol. 16, no. 4, pp. 448-451, 2002.

[12] S. H. P. P. Karunaratne, B. T. Damayanthi, M. H. J. Fareena, V. Imbuldeniya, and J. Hemingway, "Insecticide resistance in the tropical bedbug Cimex hemipterus," Pesticide Biochemistry and Physiology, vol. 88, no. 1, pp. 102-107, 2007.

[13] A. Romero, M. F. Potter, D. A. Potter, and K. F. Haynes, "Insecticide resistance in the bed bug: a factor in the pest's sudden resurgence?" Journal of Medical Entomology, vol. 44, no. 2, pp. 175-178, 2007.

[14] E. A. Omudu, "A survey of bedbug (Hemiptera: Cirnicidae infestations in some homes and hostels in Makurdi and Otupkpo, Benue State, Nigeria, with notes on public health implications," The Nigerian Journal of Pure and Applied Sciences, vol. 1, pp. 84-91, 2008.

[15] H. D. Pratt and J. W. Smith, "Arthropods of public health importance," in Diagnostic Procedure for Mycotic and Parasitic Infections, B. B. Wentworth, Ed., American Public Health Association, Washington, Wash, USA, 2005.

[16] S. W. Hwang, T. J. Svoboda, I. J. De Jong, K. J. Kabasele, and E. Gogosis, "Bed bug infestations in an urban environment," Emerging Infectious Diseases, vol. 11, no. 4, pp. 533-538, 2005.
[17] M. Masetti and F. Bruschi, "Bedbug infestations recorded in Central Italy," Parasitology International, vol. 56, no. 1, pp. 8183, 2007.

[18] World Health Organization (WHO), Public Health Significance of Urban Pests, 2009. 

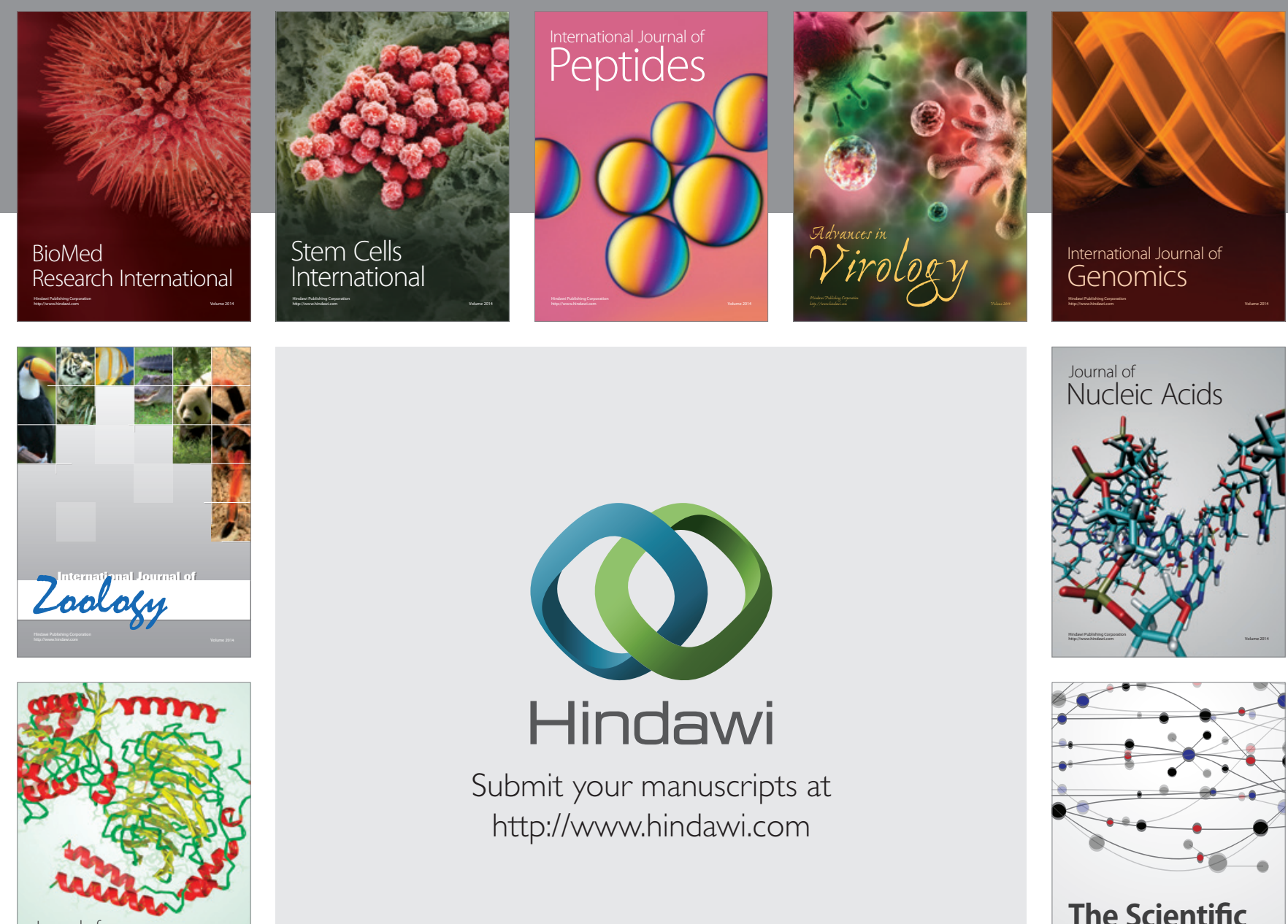

Submit your manuscripts at

http://www.hindawi.com

Journal of
Signal Transduction
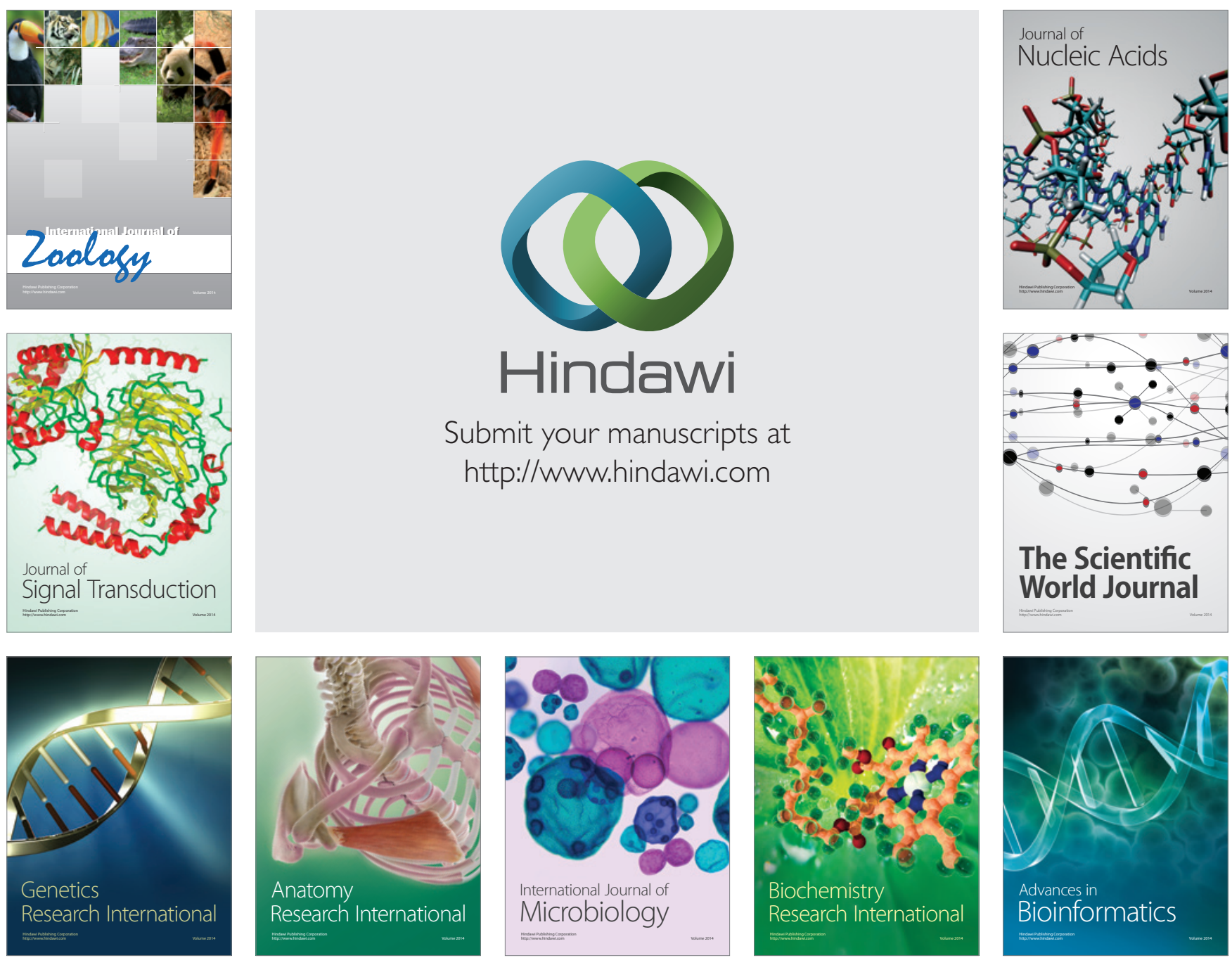

The Scientific World Journal
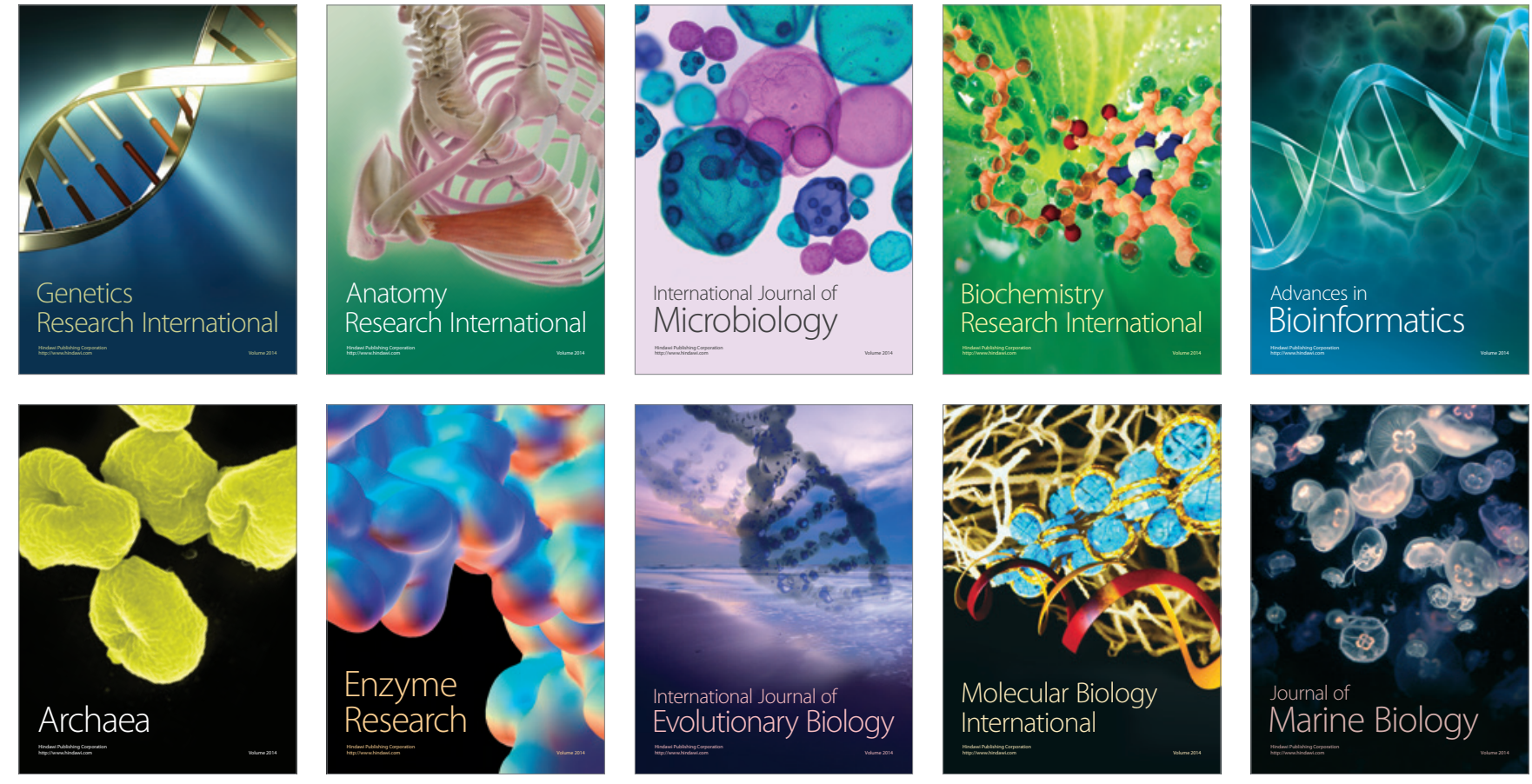